\title{
Application of trans-thoracic echocardiography and coronary CT angiography to diagnose mitral valve prolapse
}

\author{
Jingbo Li ${ }^{1}$, Yun Zhang ${ }^{2}$, Liulong Zhang ${ }^{2}$, Deyong Lv²*, Hui Song ${ }^{3}$, Haifeng Zhang ${ }^{1}$, Guangyan Zhou ${ }^{1}$ and Hong Li ${ }^{1}$
}

\begin{abstract}
Objective: At present, multi-detector cardiac CT has been widely applied in the detection of heart valve morphology and function. This study aims to compare the coronary $C T$ angiography and trans-thoracic echocardiography for patients with mitral valve prolapse.

Methods: CT angiography and trans-thoracic echocardiography were adopted to detect the movement range and thickness of valvula bicuspidalis. The ultrasonic parameters of $C T$ angiography were considered as standard reference value.

Results: Receiver operating characteristic (ROC) curve showed that the area of mitral valve motion amplitude under ROC curve was $95 \%$ detected by CT angiography with statistical significance $(P<0.001)$. Based on the intercept point on the ROC curve, the sensitivity and accuracy of mitral valve amplitude detected by CT angiography was 69.2 and $95.6 \%$, the false positive and false negative rate was 5.2 and $32.4 \%$, the predicted value of positive and negative was 92.9 and $76.9 \%$ and the consistency rate of motion range and leaf thickness detected by $C T$ angiography was 83.3 and $47.5 \%$. Trans-thoracic echocardiography showed that the thickness and motion range of mitral leaflet was (1.95 \pm 0.22$)$ $\mathrm{mm}$ and $(1.5 \pm 2.28) \mathrm{mm}$. The thickness and motion range of mitral leaflet that detected by $\subset T$ was $(2.00 \pm 0.54) \mathrm{mm}$ and $(3.76 \pm 2.1) \mathrm{mm}$.
\end{abstract}

Conclusion: The accuracy and reliability of $\mathrm{CT}$ angiography for patients with mitral valve prolapse are higher than those of trans-thoracic echocardiography.

Keywords: Trans-thoracic echocardiography, Coronary $C T$ angiography, Mitral valve prolapse

\section{Introduction}

Mitral valve prolapse is one of the most common heart valve diseases. Epidemiologic studies have demonstrated that the morbidity rate of mitral valve prolapse is approximately 3-6\%. A majority of patients have no obvious clinical manifestations. If severe mitral regurgitation occurs in the late period, the patients have to undergo mitral valve repair. Therefore, the monitoring and accurate diagnosis of high-risk patients is of great significance [1-4]. If patients with moderate or severe

\footnotetext{
* Correspondence: denysci@sina.com

2Department of Radiology, Dongying People's Hospital of Shandong, No.

317, Nan Yi Road, Dongying 257091, Shandong, China

Full list of author information is available at the end of the article
}

mitral valve prolapse were complicated with the left ventricle and decreased contractile function, the incidence rate of cardiac death events will be increased significantly. We should monitor these patients closely. The clicking sound and / or noise can be heard during the middle or late stage of systole of mitral valve prolapse. At present, trans-thoracic echocardiography has been widely regarded as a standard method of diagnosing heart valve diseases. During the detection, the displacement of mitral valve leaflet is more than $2 \mathrm{~mm}$ or the long axis direction, which tends to the atrium cordis [58]. Nevertheless, trans-thoracic echocardiography also has some limitations that it depends on the experience of operators, body size and heart rate of patients, and

(c) The Author(s). 2019 Open Access This article is distributed under the terms of the Creative Commons Attribution 4.0 International License (http://creativecommons.org/licenses/by/4.0/), which permits unrestricted use, distribution, and 
related detection device, etc [9] Multi-detector CT could diagnose abnormal diseases and functions of cardiac valves effectively, and assess coronary artery disease. The application of this method in the evaluation of mitral valve prolapse has been rarely reported [10-12]. The aim of this study is to compare and evaluate these two diagnostic techniques, which could provide guidance and reference for clinicians.

\section{Materials and methods \\ Baseline data}

From August 1st, 2014 to July 31st, 2015, patients with mitral valve prolapse by physical examination and transthoracic echocardiography were recruited. Then, valve repair surgery was carried out and re-examined by CT scan at 3 months after initial diagnosis. Exclusion criteria: patients with renal insufficiency (serum creatinine $>1.5 \mathrm{mg}$ / $\mathrm{dl}$ ), thyroid diseases, iodine allergy, progressive heart failure, atrial fibrillation and other types of arhythmia, pregnant women, those with previous history of myocardial infarction, heart ischemia or other diseases occurring in recent 3 months and those unwilling to participate in this study were excluded. The diagnosis of mitral valve prolapse was confirmed by two experienced physicians, who reviewed the results of trans-thoracic echocardiography. If the heart rate was $>70$ times/min before the examination, $\beta$-receptor blocking pharmacon (25-50 mg metoprolol) was injected to control the heart rate at 65 times $/ \mathrm{min}$. A total of 90 eiligible patients completed the study. Written informed consents were obtained from all patients or family members.

\section{Trans-thoracic echocardiography and data acquisition}

Conventional trans-thoracic echocardiography was performed by experienced physician (GE Vingmed Ultrasound, VIVID-3, General Electrics, USA). Mitral valve prolapse was defined as valve cusp displacement $>2 \mathrm{~mm}$ or the parasternal direction of the long axis tended to the left atrial direction. Mitral valve leaflet thickness was measured under two- to four-chamber view similar to CT scan. The severe degree of mitral regurgitation, enddiastole and end-systole of left ventricular volume, ejection fraction, peak pulmonary arterial pressure and other parameters were also measured.

\section{CT angiography}

Patients were processed by 64-row CT inspection after 3 months of trans-thoracic echocardiography (GE. Light speed. VCT, General Electrics, USA). The related parameters were set as followed: level alignment was $2 \times 32 \times$ $0.6 \mathrm{~mm}$; profile acquisition was $64 \times 0.6 \mathrm{~mm}$; pitch of screw thread was 0.2 ; slew time was $350 \mathrm{~ms}$; tube voltage was $120 \mathrm{kV}$; tube current time was $600 \mathrm{mAs}$. A 70-100 $\mathrm{ml}$ nonionic iodine contrast agent was applied in the detection, washed by $40 \mathrm{ml}$ physiological saline and administered via intravenous dripping at a rate of $3 \mathrm{ml} /$ seconds along the elbow vein. The bolus technique was utilized to calculate the scanning delay.

\section{CT data acquisition}

Besides the function of coronary artery with CT examination, the thickness and motion range of mitral valve leaflet were collected, which was $25-30 \%$ data during R$R$ period, because the motion range of valve cusp in this section reached the maximal value. The data was processed by the late stage of multi-planar reconstruction, we defined three-chamber plane generated in the direction of parasternal longitudinal axis wasdefined as passing through the left ventricular long axis and left ventricular outflow tract, equivalent to the left coronal oblique angle. Two-chamber plane was defined as the left ventricular geometric center vertical long axis direction, equivalent to the sagittal oblique view passing through the ventriculus sinister, left atrium and center of mitral valve. Four-chamber plane was generated by the recombining of left ventricular short axis, which was located in the middle of the left ventricle. It was defined as a transitional plane passing through the left ventricular center, diaphragm and right ventricular free wall. During the systole period (25-30\% R-R period), the maximum vertical distance was recorded between the mitral valve leaflet and annulus plane under threechamber view, equivalent to the long axis view of transthoracic echocardiography. Left ventricular offset was defined as negative value, and its left atrial offset was defined as positive value. The thickness of valve cusp was measured under two- to four-chamber view, excluding the calcified part. The explanation of checking image was finished by two experienced clinicians, who were blind to the results of trans-thoracic echocardiography.

\section{Statistical analysis}

SPSS 20.0 statistical software was utilized for data analysis. The data were expressed as mean \pm standard deviation (SD). Continuous variables were statistically compared by t-test. Classified variables were compared by chi-square test or Fisher exact test. The correlation analysis was processed by Pearson's correlation analysis examination. The ROC curve was adopted to detect the cut-off point. The sensitivity, specificity, false positive, false negative and other parameters were detected and measured. A $P$ value of less than 0.05 was considered as statistical significance.

\section{Results}

A total of 90 patients were included in the study, aged $(61.2 \pm 13.4)$ years old on average, the male/female ratio was 3:2, $(56.3 \pm 11.9)$ years old for the male and $(66.4 \pm$ 12.7) years old for the female. The average systolic pressure, diastolic pressure and heart rate before trans-thoracic 
echocardiography and CT detection were $(131 \pm 12) \mathrm{mmHg}$ vs. $(128 \pm 14) \mathrm{mmHg},(70 \pm 8) \mathrm{mmHg}$ vs. $(72 \pm 8) \mathrm{mmHg}$, $(69 \pm 10)$ times/min vs. $(68 \pm 9)$ times/min, respectively, as illustrated in Table 1.

\section{Trans-thoracic echocardiography}

Trans-thoracic echocardiography showed that the thickness and motion range of mitral leaflet were $(1.95 \pm 0.22)$ $\mathrm{mm}$ and $(1.5 \pm 2.28) \mathrm{mm}$. The cardiac examination results were regarded as the reference standard. The thickness and motion range of mitral leaflet that detected by CT were $(2 \pm 0.54) \mathrm{mm}$ and $(3.76 \pm 2.1) \mathrm{mm}$.

\section{CT angiography}

ROC analysis of the data obtained by CT angiography showed that compared with the results of trans-thoracic echocardiography, the area under standard curve of valve leaf thickness detected by CT was $57 \%(95 \% \mathrm{CI}$ : $0.42-0.76)$ with no statistical significance $(p=0.36)$. The optimal cut-off point of using CT to detect leaf thickness was $1.6 \mathrm{~mm}$. The sensitivity of mitral valve prolapse was $94.2 \%$, the specificity was $95.1 \%$, the false positive was $5.1 \%$, the false negative was $94.9 \%$, the positive predictive value (PPV) was $48 \%$ and the negative predictive value (NPV) was 52\%. The consistency between CT angiography and trans-thoracic echocardiography was $47.5 \%$.

CT angiography showed that the area of mitral valve leaflet movement amplitude under ROC curve was 95\% (95\%CI: $0.88-1.0)$ with statistical significance $(P<0.05)$. The motion range of valve cusp was a vital index of diagnosing mitral valve prolapse. The cut-off point in ROC curve was $2.5 \mathrm{~mm}$, the sensitivity of mitral valve prolapse was $69.2 \%$, specificity was $95.6 \%$, the false positive was $5.2 \%$, the false negative was $32.4 \%$, the positive predictive value (PPV) was $93.1 \%$ and the negative predictive value (NPV) was $77.8 \%$. The consistency between CT angiography and trans-thoracic echocardiography was $83.3 \%$. (Fig. 1 and 2).

Table 1 Baseline data of enrolled patients

\begin{tabular}{ll}
\hline Parameter $(n=90)$ & \\
\hline Age (years) & $61.2 \pm 13.4$ \\
Male (\%) & $54(60 \%)$ \\
BMI $\left(\mathrm{kg} / \mathrm{m}^{2}\right)$ & $26.6 \pm 3.8$ \\
No clinical symptom & $28(31.1 \%)$ \\
Had clinical symptom & $62(68.9 \%)$ \\
Related risk factors & \\
Diabetes mellitus (\%) & $9(10 \%)$ \\
High blood pressure (\%) & $32(35.6 \%)$ \\
Smoker (\%) & $40(44.4 \%)$ \\
Dyslipidemia (\%) & $22(24.4 \%)$ \\
Family medical history (\%) & $25(27.8 \%)$ \\
\hline
\end{tabular}

\section{Correlation analysis}

According to the obtained data, 70\% direct correlation existed between $\mathrm{CT}$ angiography and trans-thoracic echocardiography in the measurement of leaf thickness with statistical significance. The relativity of valve cusp motion range was $95 \%$, which also had statistical significance $(P<0.05)$.

\section{Discussion}

At present, CT detection has been used widely in clinical application, which has been utilized evaluate the coronary artery occlusion in the early stage and can improve the long-term clinical prognosis of patients. However, there is still a lack of study on mitral valve related disorders, such as the diagnostic value of mitral valve prolapse [13-16]. Before the mitral valve surgery, most patients require cardiac ultrasound examination to quantify the degree of mitral regurgitation and its anatomical characteristics. For a part of patients, they have to receive another coronary CT angiography to ensure whether the extra treatment should be delivered besides repairing valvula bicuspidalis [17-20]. Consequently, CT scan is relatively comprehensive and convenient. The aim of this study was to explore the differences between multi-slice spiral CT and trans-thoracic echocardiography in the diagnosis of mitral valve prolapse.

First, we analyzed the linear correlation between the thickness of valve cusp and advocacy motion range by Pearson's correlation analysis and the results showed significant correlation between these two methods. Moreover, we also applied statistical cross-analysis for assessing the values between CT angiography and trans-thoracic echocardiography. The results showed that $\mathrm{CT}$ angiography possessed a higher specificity for diagnosing mitral valve prolapse and an acceptable sensitivity, which was basically the same with the results of existing related literature reports. In this study, the sensitivity of using CT angiography to diagnose mitral valve prolapse was $69.2 \%$, identical to the sensitivity in Shah and other researchers' reports. However, 67 patients were included in the study by Ghosh et al and the sensitivity of mitral valve prolapse detected by CT was $92 \%$. Feuchtner et al. have demonstrated that the sensitivity in 112 patients is calculated as $96 \%$. Therefore, with the increase of sample size, the sensitivity shows a rising trend because the sample size included in this study was relatively limited, the obtained sensitivity was relatively reasonable. The selection for diabetes mellitus, high blood pressure, mammary cancer and other diseases with high morbidity and death rate always required the detection methods with high sensitivity, while it was not needed to select for mitral valve prolapse, but the related study on large sample was still significant.

In this study, the specificity of mitral valve prolapse detected by CT angiography was $95.6 \%$, the specificity in Shah, Ghosh, Feuchtner and other researchers' investigations was 


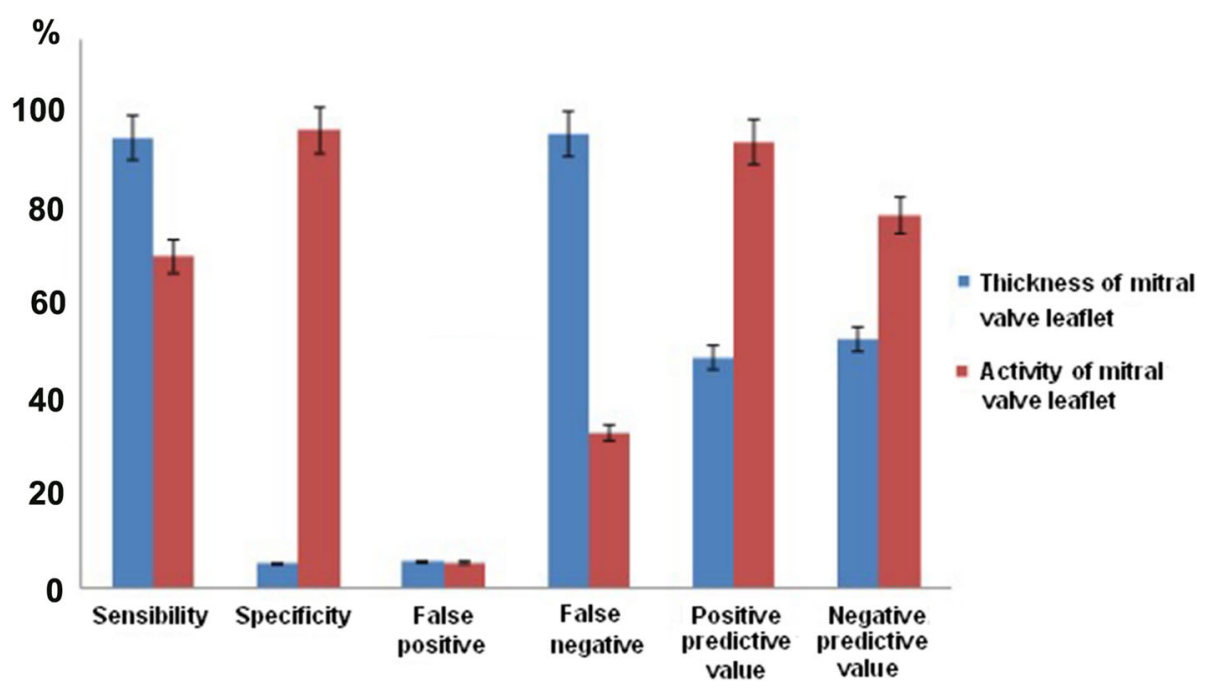

Fig. 1 Relevant data percentage of mitral valve prolapse judged by mitral valve thickness and activity in CT detection

100, 97.1 and 93\%, respectively. Consequently, CT was a relatively reliable method for diagnosing mitral valve prolapse, and the related false positive rate was low. The PPV of this detection method was higher (93.1\%), but when applied CT angiography for detecting mitral valve leaflet movement ( $>2.5 \mathrm{~mm}$ in this study), the diagnosis of mitral valve prolapse was established. The PPV in previous study was 87,80 and $93 \%$. The NPV in this study was $77.8 \%$, which was basically the same with the result of 80,83 and $91 \%$ in previous study. In the detection of mitral valve thickness, the relativity of these two methods was $70 \%$, which indicated that the reliability of diagnosing mitral valve thickness was pretty well. The overall accuracy of

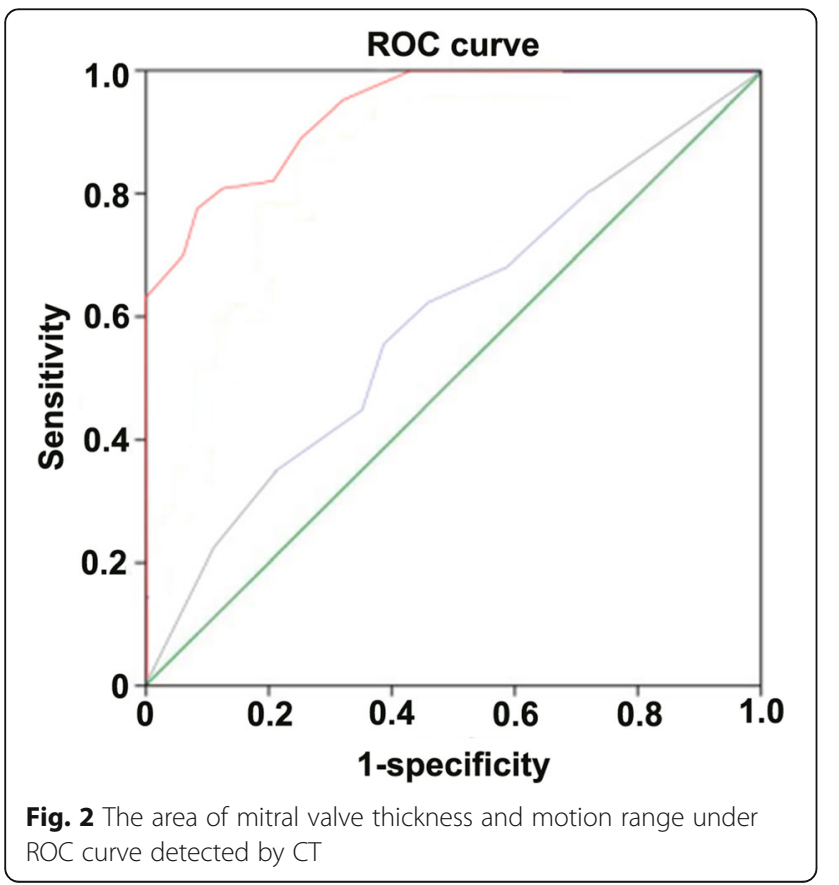

mitral valve prolapse detected by CT angiography was $83.3 \%$, so it was a reliable detection method.

\section{Conclusions}

CT also has the advantage of less radiation exposure, side effects of contrast agent and lower cost, etc [20-24] The results of this study show that the accuracy and reliability of CT angiography for patients with mitral valve prolapse are higher than those of trans-thoracic echocardiography. CT angiography is a reliable method to deliver a diagnosis of mitral valve prolapse.

\section{Study limitation}

This is a retrospective investigation. Therefore, the preliminary findings obtained in current article remain to be further validated in a prospective study. In addition, the detection methods can be widened and the sample size can be enlarged to confirm the obtained conclusion.

\section{Abbreviations}

NPV: negative predictive value; PPV: positive predictive value; SD: standard deviation

\section{Acknowledgements}

Not applicable.

Authors' contributions

All authors read and approved the final manuscript

\section{Funding}

Not applicable.

Availability of data and materials

The datasets used and/or analysed during the current study are available from the corresponding author on reasonable request.

Ethics approval and consent to participate

All the operations in this study were informed and agreed by patients, family members and the ethics committee of our hospital. 


\section{Consent for publication}

Not applicable.

\section{Competing interests}

The authors declare that they have no competing interests.

\section{Author details}

'Department of Ultrasound, Dongying People's Hospital of Shandong, Dongying 257091, China. 'Department of Radiology, Dongying People's Hospital of Shandong, No. 317, Nan Yi Road, Dongying 257091, Shandong, China. ${ }^{3}$ Department of Ultrasound, Anorectal Disease Hospital, Victory Petroleum Administration Bureau, Dongying 257077, China.

Received: 21 November 2018 Accepted: 30 May 2019

Published online: 24 June 2019

\section{References}

1. Izumo M, Shiota M, Kar S, et al. Authors. Comparison of real-time threedimensional transesophageal echocardiography to two-dimensional transesophageal echocardiography for quantification of mitral valve prolapse in patients with severe mitral regurgitation. Am J Cardiol. 2013;111:588-94.

2. Avierinos JF, Gersh BJ, Melton $\sqcup$, et al. authors Natural history of asymptomatic mitral valve prolapse in the community. Circulation. 2002;106:1355-61.

3. Ciancamerla F, Paglia I, Catuzzo B, et al. Sudden death in mitral valve prolapse and severe mitral regurgitation. Is chordal rupture an indication to early surgery? J Cardiovasc Surg. 2003:44:283-6.

4. Freed LA, Benjamin EJ, Levy $D$, et al. authorsMitral valve prolapse in the general population: the benign nature of echocardiographic features in the Framingham heart study. J Am Coll Cardiol. 2002:40:1298-304.

5. Janne d'Othée B, Siebert U, Cury R, Jadvar $H$, et al. A systemati review on diagnostic accuracy of CT-based detection of significant coronary artery disease. Eur J Radiol. 2008:65:449-61.

6. Raff GL, Gallagher MJ, O'Neill WW, et al. Diagnostic accuracy of noninvasive coronary angiography using 64- slice spiral computed tomography. J Am Coll Cardiol. 2005;46:552-7.

7. Alkadhi $\mathrm{H}$, Wildermuth $\mathrm{S}$, Bettex DA, et al. Authors. Mitral regurgitation: quantification with 16-detector row CT - initial experience. Radiology. 2006; 238:454-63.

8. Messika-Zeitoun D, Serfaty JM, Laissy JP, et al. Authors. Assessment of the mitral valve area in patients with mitral stenosis by multislice computed tomography. J Am Coll Cardiol. 2006;48:411-3.

9. Wheatley $\mathrm{GH}$, Opie SR, Maas D, et al. Detection of unsuspected mitral valve prolapse using 64 multi-slice computed tomography. Ann Thorac Surg. 2007:83:1555.

10. Guiling $\mathrm{H}$, Gexin S, Jianping L. Advances in low radiation dose techniques for cardiac CT imaging. Chin J Gerontol. 2010(1):457-9.

11. Zhihong L, Xiaoli S, Lifang L, Guowei, Panling, Chenbin. Ultrasound evaluation of adolescent idiopathic mitral valve prolapse and its correlation with HLA [J]. Journal of cardiovascular rehabilitation medicine. 2002;11(4):320-3.

12. Ghosh N, Al-Shehri H, Chan K, Mesana T, et al. Authors. Characterization of mitral valve prolapse with cardiac computed tomography: comparison to echocardiographic and intraoperative findings. Int J Cardiovasc Imaging. 2012;28:855-63.

13. Feuchtner GM, Alkadhi H, Karlo C, et al. Authors. Cardiac CT angiography for the diagnosis of mitral valve prolapse: comparison with echocardiography1. Radiology. 2010;254:374-83.

14. Shah RG, Novaro GM, Blandon RJ, et al. Mitral valve prolapse: evaluation with ECG-gated cardiac CT angiography. AJR Am J Roentgenol. 2010;194:579-84.

15. Yinghong J, Chenxu W, Hanmei J. Application of two dimensional and three dimensional echocardiography in the diagnosis of left atrioventricular valve prolapse in surgical operation. Journal of practical cardiovascular and pulmonary vascular diseases. 2011;19(5):813-4.

16. Freed LA, Levy D, Levine RA, Larson MG, et al. Authors. Prevalence and clinical outcome of mitral-valve prolapse. N Engl J Med. 1999;341:1-7.

17. Wei J, Hsiung MC, Tsai SK, Ou CH, Chang CY, et al. The routine use of live three-dimensional transesophageal echocardiography in mitral valve surgery: clinical experience. Eur J Echocardiogr. 2010;11:14-8.

18. Enriquez-Sarano M, Avierinos JF, Messika-Zeitoun D, et al. Quantitative determinants of the outcome of asymptomatic mitral regurgitation. $N$ Engl J Med. 2005;352:875-83.
19. Bonow RO, Carabello BA, Chatterjee K, et al. ACC/AHA 2006 guidelines for the Management of Patients with Valvular heart disease. A report of the American College of Cardiology/American heart Assocation task force on practice guidelines; Society of Cardiovascular Anesthesiologists. J Am Coll Cardiol. 2006;48:e1-e148.

20. Weiwei Z, Yajun L, Xiaodong X, Yingying P, Shanbo W, Lisa. The classification and clinical significance of two dimensional and color Doppler on atrioventricular valve prolapse. Chin J Med Imag Technol. 2000;16(4): 289-90.

21. Vahanian $\mathrm{A}$, Baumgartner $\mathrm{H}, \mathrm{Bax} J$, et al. Guidelines on the management of valvular heart disease. The task force on the management of Valvular heart disease of the European Society of Cardiology. Eur Heart J. 2007;28:230-68.

22. Delabays $A$, Jeanrenaud $X$, Chassot $P G$, et al. Localization and quantification of mitral valve prolapse using three-dimensional echocardiography. Eur J Echocardiogr. 2004;5:422-9.

23. Pepi M, Tamborini G, Maltagliati A, et al. Head-to-head comparison of two- and three-dimensional transthoracic and transesophageal echocardiography in the localization of mitral valve prolapse. J Am Coll Cardiol. 2006;48:2524-30.

24. Uno K, Takenaka K, Ebihara A, Nawata K, et al. Value of live 3D transoesophageal echocardiography in the diagnosis of mitral valve lesions. Eur J Echocardiogr. 2009;10:350-1.

\section{Publisher's Note}

Springer Nature remains neutral with regard to jurisdictional claims in published maps and institutional affiliations.

Ready to submit your research? Choose BMC and benefit from:

- fast, convenient online submission

- thorough peer review by experienced researchers in your field

- rapid publication on acceptance

- support for research data, including large and complex data types

- gold Open Access which fosters wider collaboration and increased citations

- maximum visibility for your research: over $100 \mathrm{M}$ website views per year

At BMC, research is always in progress.

Learn more biomedcentral.com/submissions 